\title{
El 'forum shopping' entre la OMC y los TLC. El valor del principio de la cosa juzgada en la solución de controversias ${ }^{1}$
}

\author{
JosÉ JULIÁN TOLE
}

En el contexto de las actuales relaciones del comercio internacional, no hay duda de que existe una mayor propensión a conflictos entre normas del sistema multilateral del comercio, o lo que en este escrito se denomina el "Derecho de la $\mathrm{OMC}^{\prime \prime}{ }^{3}$, y otras normas internacionales (en materia de medio ambiente ${ }^{4}$, de derechos humanos ${ }^{5}$, de normas laborales $^{6}$, de normas comunitarias, de normas regionales, etc.). El aumento de estos

1 Este documento fue elaborado en el marco del Seminario SLADI 2015. Para citar el artículo: Tole Martínez, J. (2016). El 'forum shopping' entre la OMC y los TLC. El valor del principio de la cosa juzgada en la solución de controversias, en Revista Con-Texto, n. ${ }^{\circ} 46$ EE, pp. 157-179. DOI: https://doi.org/10.18601/01236458.n46EE.09

2 Julián Tole Martínez, docente-investigador, abogado y máster en Derecho de la Universidad Externado de Colombia, máster y doctor en Derecho Internacional Económico de la Universidad de Barcelona (España), especialista en Comercio Exterior e investigador invitado de la Universidad Nacional Autónoma de México (UNAM).

3 El término "derecho de la OMC" puede definirse, a grandes rasgos, como el cuerpo normativo consagrado en los "acuerdos abarcados" de la OMC.

4 En efecto, existe un importante número de autores que analizan los conflictos de normas de la OMC con Acuerdos de Medio Ambiente, entre ellos: Marceau, Gabrielle. Conflicts of Norms and Conflicts of Jurisdictions: The Relationship between the WTO Agreement and MEAs and Other Treaties. En: Journal of World Trade. vol. 35, n. ${ }^{\circ}$ 6, 2001; BraCK, DunCAN y GraY, Kevin. Multilateral Environmental Agreements and the WTO, Report of the Royal Institute of International Affairs, 2003; BuSSE, MATHIAS. Trade, Environmental Regulations and the World Trade Organization: New Empirical Evidence. En: Journal of World Trade, vol. 38, n. ${ }^{\circ}$ 2, 2004. pp. 285-306; WIERS, JOCHEM. Trade and Environment in the EC and the WTO, A Legal Analysis. Groningen: Europe Law Publishing, 2003, entre otros.

5 Tistounet, ERIC. The Problem of Overlapping among Different Treaty Bodies. En: Alston, P. y CRAWFORD, J. (eds.). The Future of un Human Rights Treaty Monitoring. Cambridge: Cambridge University Press, 2000, pp. 383-401; Petersmann, ERnst-Ulrich. The WTO Constitution and Human Rights. En: Journal of International Economic Law, vol. 3, 2000, pp. 19-25.

6 Compa, Lance y Diamond, Stephen (eds.). Human Rights, Labour Rights, and International Trade. Philadelphia: University of Pennsylvania Press, 1996; MOORMAN, YASMIN. Integration of ILO Core Rights Labour Standards into the WTO. En: Columbia Journal of Transnational Law, vol. 39, n. ${ }^{\circ}$ 2, 2001, pp. 555-583. 
instrumentos internacionales, de los cuales se tiene noticia todos los días, hace necesaria una clarificación de sus complejas relaciones en el marco del Derecho Internacional, pues como tratados independientes tienen un mismo rango jurídico ${ }^{7}$, esto es, son normas donde no existe una relación de jerarquía intrínseca o superioridad de una fuente de producción jurídica sobre otra ${ }^{8}$, a menos que esté contemplada de forma expresa en su instrumento, o que se pueda deducir de forma implícita de su contenido normativo por medio de la actividad interpretativa.

Bajo este panorama, una de las discusiones más significativas que se da en el marco del Derecho de la OMC son los efectos de las relaciones, los solapamientos o las superposiciones normativas con los Acuerdos Comerciales Regionales (en adelante ACR) que regulan procesos de integración, que según DAVEY y SAPIR generan situaciones calificadas de "doble incumplimiento", pues vulneran tanto obligaciones de un ACR como obligaciones de la OMC. Esto explica que los mecanismos de solución de diferencias multilaterales y regionales tengan jurisdicción sobre la misma medida ${ }^{9}$, y que se puedan activar de manera simultánea o sucedánea ${ }^{10}$.

Para encontrar algunas respuestas a los cuestionamientos de estas relaciones, solapamientos o superposiciones, es necesario analizar los propios acuerdos de la OMC y de los ACR, e inclusive el Derecho Internacional general. Así lo entiende PAUWELYN, al señalar que: "[...] few if any will question today that WTO agreements set out legally binding rules part of public international law (PIL). The WTO is not some economic bargain between governmental trade elites without normative value. It is a legally binding treaty squarely within the wider corpus of international law. As compared to the original GATT, the WTO

7 YA QIN, JULIA. Managing conflicts between rulings of WTO and RTA Tribunals: reflections on the BrazilTyres case. En: Legal Studies Research Paper Series n. ${ }^{\circ}$ 09-24. Wayne State University Law School, 2009, p. 37; Mariño MÉndeZ, Fernando. Derecho Internacional Público. 4 ed. Madrid: Trotta, 2005; Carrillo Salcedo, Juan Antonio. Reflections on the Existence of a Hierarchy of Norms in International Law. En: European Journal of International Law, vol. 8, n. ${ }^{\circ}$, 1997.

8 En palabras de COMBACAU, la normativa internacional es relativa, debido a que su ámbito de aplicación varía de acuerdo a los compromisos de cada Estado. Cfr. Combacau, Jean y Sur, Serge. Droit international public, Coll. Domat droit public. 8 ed. París: Montchrestien, 2008. p. 26. Además, las normas internacionales de ninguna manera se diferencian entre sí por su valor jurídico, sus efectos.

9 DaveY, William y SaPIR, ANDrÉ. The Soft Drinks Case: The WTO and Regional Agreements. En: World Trade Review, vol. 8, n. ${ }^{\circ}$ 1, 2009. p. 23. El problema de la superposición se refleja en la famosa disputa "MOX PLANT" que enfrenta a Irlanda y Reino Unido por la autorización del reprocesamiento de combustible nuclear en una planta ubicada en el mar de Irlanda, cuestión que fue impugnada en tres jurisdicciones diferentes que operaban bajo tres regímenes internacionales independientes.

10 Tal escenario modifica el tradicional análisis individual de los instrumentos internacionales, sus instituciones u órganos, llamando la atención sobre todo la proliferación de mecanismos de solución de diferencias. Cfr. PAuwelyn, JoOst. Bridging Fragmentation and Unity: International Law as a Universe of Inter-connected islands. En: Michigan Journal of International Law, vol. 25, 2004, p. 904. Asimismo, cfr., Grupo de Estudio de la Comisión de Derecho Internacional. Fragmentación del Derecho internacional: dificultades derivadas de la diversificación y expansión del Derecho internacional. Naciones Unidas, Documento A/CN.4/L.682, 2006, Asamblea General, 58 período de sesiones, 13 abril 2006. 
has, indeed, been 'legalized' and, like the proverbial lost son, been re-introduced into the broader family of PIL. During this process the system had a lot to learn from PIL [...]"11.

Lo anterior también se reconoce por el Órgano de Apelación de la OMC, al expresar en el asunto Estados Unidos - Gasolina, que el Derecho de la OMC no se debe interpretar en forma que dependen en última instancia de la voluntad o la aceptación de cada Estado. Para DupuY, se trata de un triple fenómeno de no-diferenciación o, más exactamente, de equivalencia: (a) equivalencia de las normas jurídicas entre sí, (b) equivalencia de las normas para la expedición de estas y (c) equivalencia de las fuentes del Derecho Internacional entre sí "clínicamente aislada" de Derecho Internacional ${ }^{12}$ (cfr. DupuY, Pierre-Marie. Droit international public. 9 ed. Dalloz, 2008, pp. 15-16). Se debe subrayar, además, que la influencia y la referencia al Derecho Internacional incluye los principios generales del Derecho y las normas relativas a la resolución de conflictos ${ }^{13}$.

Con el propósito de delimitar el objeto de análisis de las discusiones que se presentan en las relaciones entre el régimen jurídico de la OMC y de los ACR, este documento se centra en el estudio de las normas de "conflicto de jurisdicciones o competencia"14 incorporadas, primero, en el Derecho de la OMC, y segundo, en los Tratados de Libre Comercio de: América del Norte (TLCAN) de 1994; Chile y los Estados Unidos (en adelante TLC Chile - EE UU) de 2004; la República Dominicana, Centroamérica y los Estados Unidos (en adelante CAFTA - RD) de 2006; Perú y los Estados Unidos (en adelante TLC Perú - EE UU) de 2009; Colombia y los Estados Unidos (en adelante TLC Colombia - EE Uu) de 2012, y Panamá y los Estados Unidos (en adelante TLC Panamá - EE UU) de 2012; además, los Acuerdos de Asociación Económica de: la Unión Europea y México (en adelante TLC México - UE) de 2000 y la Unión Europea y Chile (en adelante TLC Chile - UE)

11 Pauwelyn, Joost. How Binding is WTo Rules? A Transatlantic Analysis of International Law. Duke Law Faculty Scholarship, Paper 1315 presented at the University of Tübingen, Conference on Changing Patterns of Authority in the Global Political Economy, 14-16 October 2004, p. 1. Disponible en internet: http://scholarship.law.duke.edu/faculty_scholarship/1315

12 Informe del Órgano de Apelación, en el asunto Estados Unidos - Pautas para la gasolina reformulada y convencional (WT/DS2/AB/R), adoptado el 29 de abril de 1996, p. 17.

13 PaumelYn, Joost. The Role of International Law in the WTO - How Far can we go?. En: American Journal of International Law, vol. 95, no. 3, 2001; MCRAE, Donald. The WTO in International Law: Tradition Continued or New Frontier? En: Journal of International Economic Law, vol. 3, n. ${ }^{0} 1,2000$, pp. 27-41, Petersmann, Ernst-Ulrich. Dispute Settlement in International Economic Law-Lessons for Strengthening International Dispute Settlement in Non- Economic Areas. En: Journal of International Economic Law, vol. 2, n. ${ }^{\circ} 2,1999$, pp. 189-248; JACKSON, JOHN H. The World Trading System, Law and Policy of International Economic Relations. 2 ed. Cambridge, MA, y London: MIT Press, 1997, pp. 25 y ss.

14 Para ZAPATERO, los conflictos entre jurisdicciones internacionales pueden ocurrir entre las decisiones (actos) o la jurisprudencia (actos reiterados) de diversos procedimientos; además, existen tres tipos de conflictos posibles: (a) entre el contenido sustantivo de un determinado acto adoptado por un mecanismo de solución de diferencias con un acto de otro mecanismo; (b) entre el contenido sustantivo de un acto específico de un mecanismo de solución de diferencias con la jurisprudencia de otro, y (c) entre los contenidos sustantivos de jurisprudencia de diferentes mecanismos de solución de diferencias. Cfr. Zapatero, Pablo. Derecho del Comercio Global. Madrid: Civitas, 2003, p. 381. 
de 2005. Agotado el mencionado estudio, se presentarán algunas reflexiones en torno al valor que tiene el principio general del derecho de la cosa juzgada o res judicata, y si este principio permite dar respuesta a los vacíos y a las limitaciones de las "normas de conflicto de jurisdicciones".

Para entender mejor estas cuestiones, a continuación se examinan las normas de conflicto de jurisdicción del Derecho de la OMC y de los TLC estadounidenses y los TLC europeos, que pueden presentarse de dos maneras: a) cláusula de selección del foro o b) cláusula de exclusión del foro.

\section{LA CLÁUSULA DE SELECCIÓN DEL FORO O EL 'FORUM SHOPPING' ENTRE LA JURISDICCIÓN DE LA OMC Y LA JURISDICCIÓN DE LOS TLC}

Como bien lo advierten KWAK y MARCEAU, los conflictos de jurisdicciones entre mecanismos de solución de diferencias que permiten elegir entre diversos procedimientos pueden llevar a dificultades relacionadas con el forum shopping, en especial, cuando las partes contendientes tienen la posibilidad de optar entre dos órganos judiciales o entre dos jurisdicciones diferentes por los mismos hechos, bien sea accionándolos en paralelo o en secuencia ${ }^{15}$. Circunstancias que generan problemas en dos niveles: que dos foros reclamen o se atribuyan la "jurisdicción final" sobre el asunto, y que estos foros puedan llegar a soluciones diferentes o, incluso, resultados opuestos.

La posibilidad de elegir foros o forum shopping ${ }^{16}$, en términos del profesor SHANY, es una manifestación legítima de la autonomía de una parte, que contribuye a una mayor utilización de los sistemas judiciales, y además es un efecto del llamado fenómeno de la fragmentación del Derecho Internacional que, con frecuencia, tiene diferentes puntos de encuentro o interacción, entre ellos el ámbito de la solución de controversias concurrentes, dando paso a la presencia de múltiples procedimientos simultáneos o secuenciales ${ }^{17}$. Existen otras lecturas del fenómeno, como la posición del profesor ZAPATERO,

15 KwaK, Kyung y Marceau, Gabrielle. Overlaps and Conflicts of Jurisdiction between the WTO and RTAs. En: Bartels, L. y Ortino, F. (eds.). Regional Trade Agreements and the WTO Legal System. New York: Oxford University Press, 2006. p. 467.

16 En el presente estudio se asume el concepto amplio de forum shopping, es decir, de acuerdo con la definición que encontramos en Black's Law Dictionary, "when a party attempts to have his action tried in a particular court or jurisdiction where he feels he will receive the most favourable judgment or verdict". Cfr. Black, Henry y Garner, Bryan. Black's Law Dictionary. 9 ed. West Publishing, 2009.

17 Shany, Yuval. The Competing Jurisdictions of International Courts and Tribunals, International Courts and Tribunals Series. Oxford University Press, 2004, pp. 230 y ss. De hecho, para algún sector de la literatura especializada del Derecho Internacional, el auge y superposición de tribunales internacionales es un "luxury problem", ante todo bienvenido, ya que múltiples tribunales son mucho mejor que una ausencia total de estos. Cfr. Higgins, Rosalyn. A Babel of Judicial Voices? Ruminations from the Bench. En: International and Comparative Law Quarterly, vol. 55, 2006; SreenivaSA RaO, Pemmaraju. Multiple International Judicial Forums: A Reflection of the Growing Strength of International Law or its Fragmentation?. En: Michigan Journal of International Law, vol. 25, 2004; KARAGIANNIS, SYMÉON. La Multiplication des Juridictions Internationales: Un Système Anarchique? Société Française pour le Droit International (ed.), 2003. 
que entiende: "[...] la concurrencia de acuerdos internacionales así como la coordinación de sus respectivos procedimientos de solución de diferencias como un asunto complejo y, por ello, se hace difícil llegar a articular un compromiso jurídico definitivo sobre las 'pasarelas' entre los sistemas jurídicos y jurisprudenciales"18.

Aún más crítica es la posición de Guillaume (expresidente de la Corte Internacional de Justicia), quien expresa su preocupación acerca de la posibilidad de que el forum shopping pueda dar lugar a un "mercado" impulsado por el deseo de competir entre los foros para ser el más "popular", que a su vez puede afectar negativamente a la calidad de las decisiones judiciales ${ }^{19}$.

Independientemente de la posición doctrinal que se asuma, para hablar del forum shopping es necesario que se cumplan ciertas condiciones, como son: que las partes en conflicto se encuentren vinculadas por más de un régimen jurídico internacional o ratione personae; que las normas de estos regímenes regulen la misma cuestión de fondo en controversia $\mathrm{o}$, en otras palabras, que exista una identidad ratione materiae, $\mathrm{y}$, finalmente, que estas normas existan o interactúen al mismo tiempo, es decir, una superposición ratione tempori ${ }^{20}$.

De las anteriores condiciones, la que requiere más reflexión para determinar si existe forum shopping entre el mecanismo de la OMC y los procedimientos de los TLC estadounidenses y europeos es la ratione materiae ${ }^{21}$, en tanto que es posible encontrar cualquiera de las siguientes situaciones: normas de los TLC que sean independientes de las normas de la OMC o, en otras palabras, las obligaciones, prohibiciones o derechos de los TLC no se reconocen o no están regulados por las normas multilaterales; normas de los TLC que van más allá de las normas incorporadas en la OMC, o las llamadas disposiciones OMCplus; normas de los TLC que son una confirmación de las normas de la OMC, donde se encuentran las normas de remisión, normas de los TLC que están implícitamente extraídas de las normas de la OMC, es decir, aquellas normas en los TLC que sin hacer un reenvío a normas multilaterales, las reproducen literalmente.

En este complejo catálogo de normas que se relacionan de diferentes maneras entre sí, se pueden presentar potenciales conflictos entre tratados y/o superposición de

ZAPATERO. Op. cit., nota 13, p. 231.

19 Guillaume, Gilbert. Advantages and Risks of Proliferation: A Blueprint for Action. En: Journal of International Criminal Justice, vol. 2, 2004, pp. 300-303.

20 Para profundizar en las condiciones que tiene el forum shopping, cfr. PAuWelyn, JoOST y SALLES, LuIZ EduARDo. Forum Shopping before International Tribunals: (Real) Concerns, (Im) Possible Solutions. En: Cornell International Law Journal, vol. 42, 2009; Piérola, Fernando y Horlick, Gary. Dispute Settlement in the WTO and in 'North-South' Agreements of the Americas: Considerations for the Choice of Forum. En: Journal of World Trade, vol. 41, n. ${ }^{\circ}$ 5, 2007; SHAnY. Op. cit., nota 16; PAuWelYN, JOOST. Going Global or Regional or Both? Dispute settlement in the Southern African Development Community (SADC) and Overlaps with other Jurisdictions. En: Minnesota Journal of Global Trade, vol. 13, n. ${ }^{\circ}$ 2, 2004, pp. 231-304.

21 La primera (ratione personae) y tercera (ratione tempori) condición se explican por sí mismas. Todos los Estados partes en un TLC estadounidense o europeo están vinculados por los Acuerdos de la OMC e interactúan al mismo tiempo. El segundo requisito (ratione materia) requiere más atención, pues depende de qué se entiende por la "misma controversia", ya sea controversia de iure o controversia de facto. Cfr. PIÉROLA y HORLICK. Op cit. 
jurisdicciones ${ }^{22}$. Así por ejemplo, respecto a controversias en el primer y el segundo tipo de normas no hay ningún problema, ya que tan solo pueden ser juzgadas mediante los procedimientos señalados en los TLC estadounidenses y los TLC europeos. Por el contrario, para las diferencias concernientes a las dos últimas normas (que confirman o que reproducen normas de la OMC), existe la posibilidad de elegir entre la jurisdicción de la OMC o la jurisdicción de los TLC antes señalados ${ }^{23}$.

Dicho esto, un punto de partida lógico para determinar el alcance y las posibilidades del forum shopping es considerar los términos en que cada TLC estadounidense y europeo bajo estudio regula estas normas de conflicto de jurisdicciones ${ }^{24}$. Sin duda, existe una regla general en estos acuerdos: la incorporación de cláusulas de selección del foro; así se observa en los artículos 2005.1 del TLCAN, 22.3(1) del TLC Chile - EE UU, 20.3(1) del CAFTA - RD, 21.3(1) del TLC Perú - EE UU y 21.3(1) del TLC Colombia - EE UU, en los cuales se reproduce de manera análoga que: "[...] cualquier controversia que surja en relación con estos tratados y cualquier otro acuerdo de libre comercio al que las partes contendientes pertenezcan o el Acuerdo sobre la OMC, la Parte reclamante podrá elegir el foro para resolver la controversia".

Como se puede advertir, los TLC estadounidenses establecen una cláusula de carácter uniforme, redactada para no excluir ulteriores mecanismos de solución de diferencias, que, al mismo tiempo, permite que las diferencias puedan resolverse mediante tres foros: a) el sistema de solución de diferencias de la OMC, b) el propio mecanismo del acuerdo y c) otros procedimientos de cualquier acuerdo en el que las partes en conflicto sean signatarias ${ }^{25}$.

Hay que precisar que la cláusula de selección del foro en el TLCAN tiene algunas ambigüedades respecto a los demás TLC estadounidenses, ya que en el párrafo 2 del artículo 2005 se regula que las diferencias se resolverán "normalmente" en el marco del

22 En la discusión de cuestiones de jurisdicción, la doctrina especializada utiliza a menudo el término conflicto de manera intercambiable con superposición. Cfr. PAuWElYN. Op. cit., nota 19, p. 231; KWAK y MarCEAU. Op. cit., nota 14, pp. 465-524; HenCKELS, CAROLINE. Overcoming Jurisdictional Isolationism at the WTO-FTA Nexus: A Potential Approach for the WTO. En: The European Journal of International Law, vol. 19, n. ${ }^{\circ} 3,2008$.

23 Bercero García, Ignacio. Dispute Settlement in European Union Free Trade Agreements: Lessons Learned? En: Bartels, L. y Ortino, F. (eds.). Regional Trade Agreements and the WTO Legal System. Nueva York: Oxford University Press, 2006, pp. 399-401; Trebilcock, Michael y Owse, Robert. Regulation of International Trade. 3 ed. Routledge Edition, 2005, pp. 142 y ss.

24 Según el profesor Mus, mediante las normas de conflicto se determina la posición jurídica de alguno o todos los preceptos del tratado negociado en relación con algunas o todas las normas de otros tratados en vigor o futuros. Cfr. Mus, JAN B. Conflicts between Treaties in International Law. En: Netherlands International Law Review, vol. 45, n. ${ }^{\circ} 2,1998$, pp. 227-232.

25 Es necesario aclarar que el TLCAN, en su artículo 2005.1, solamente regula dos foros, es decir, los mecanismos del propio TLCAN y el sistema de solución de diferencias de la OMC. Cfr. LeÓn STEFfENS, AvELINO. La elección del foro en el Tratado de Libre Comercio de América del Norte y los resultados de la Ronda Uruguay del gatT. En: López Ayllón, Sergio. El futuro del Libre Comercio en el Continente Americano, análisis y perspectivas. México: Universidad Nacional Autónoma de México, Instituto de Investigaciones Jurídicas, 1997, pp. 305 y ss. 
TLCAN cuando: a) la parte demandada prefiere resolverla bajo el capítulo XX y b) los fundamentos invocables, tanto en el procedimiento de la OMC como del TLCAN, sean "sustancialmente equivalentes" 26 . A pesar de la ambigüedad en la redacción de la norma (concretamente en los enunciados "normalmente" y "sustancialmente equivalentes"), la cláusula de selección del foro, en la práctica, se aplica en todos los casos en que el TLCAN no incorpora una cláusula especial de exclusión del foro que impida acudir al sistema de solución de diferencias de la $\mathrm{OMC}^{27}$. Estas cláusulas rigen para los siguientes ámbitos: sector agropecuario y medidas sanitarias y fitosanitarias (sección B del capítulo VII,); medidas relativas a normalización, concretamente, en las diferencias sobre estándares relativos a la protección de la vida o la salud humana, animal o vegetal o del medio ambiente y, además, cuestiones de hecho relacionadas con el medio ambiente, la salud, la seguridad o la conservación, incluyendo las cuestiones científicas directamente relacionadas (cap. IX), y tratados en materia ambiental y de conservación (art. 104).

Estas cláusulas de foro exclusivo en el TLCAN no tienen, en principio, ninguna ventaja para México, toda vez que limitan sus posibilidades de acudir al mecanismo de la OMC en los temas más sensibles para el comercio.

La cláusula uniforme en los TLC estadounidenses determina que la elección del foro únicamente corresponde a la "parte reclamante", dado que es en su escrito presentado ante a la Comisión (cuando las partes no han logrado resolver el asunto por medio de las consultas) y, posteriormente, en su escrito que incorpora el mandato o los términos de referencia ${ }^{28}$, donde se define el alcance o la naturaleza de la controversia, al identificar: quién origina la controversia (parte demandada), qué provoca el incumplimiento de las obligaciones o la medida incompatible o qué anula beneficios (objeto de la controversia) y dónde se dirime la solución de la controversia (selección del foro) ${ }^{29}$. Lógicamente, esta legitimación de la "parte reclamante" solo procede para las controversias en los

27 El artículo 2005.3 del TLCAN regula cláusulas especiales de exclusión del foro que dan "primacía" al mecanismo de la OMC en caso de que la parte demandada "[...] solicite por escrito que el asunto se examine en los términos de este Tratado, la parte reclamante podrá solo recurrir en lo sucesivo y respecto de ese asunto, a los procedimientos de solución de controversias de este Tratado".

28 El mandato o los términos de referencia tienen diferentes efectos jurídicos: (a) movilizan el aparato institucional del procedimiento de solución de controversias (dado que ni el panel o grupo arbitral ni la Comisión pueden iniciar este procedimiento); (b) delimitan el alcance o naturaleza de la controversia, es decir, definen el objeto (la medida u otro asunto que origina la reclamación e indica las disposiciones del Tratado que considere aplicables) y sujetos procesales (determinan quiénes son la parte reclamante y la parte demandada), y (c) radican la competencia o la vía procesal, por la cual se resuelve la controversia. Cfr. Tole MartíneZ, Julián. Solución de controversias en los TlC. Aportes del Derecho de la OMC. Bogotá D.C.: Universidad Externado de Colombia, 2014.

29 Según el profesor WiTKER en el Derecho Procesal General y en los mecanismos de solución de controversias, el factor objetivo constituye uno de los criterios orientadores más importantes para atribuir la competencia. Cfr. WiTKer, Jorge. Panorama general de solución de controversias en el comercio internacional contemporáneo. En: WITKER, J. (coord.). Resolución de controversias comerciales en América del Norte. México: Universidad Nacional Autónoma de México, Instituto de Investigaciones Jurídicas, 1997, p. 36. 
TLC bilaterales, dado que la regla varía cuando se trata acuerdos plurilaterales (como el TLCAN O CAFTA - RD) $)^{30}$.

Adicionalmente, estas cláusulas de selección del foro de los TLC estadounidenses tienen una estructura de doble vía: "derecho-deber". Por un lado, otorgan a la parte reclamante la posibilidad de elegir el foro que más le convenga para solucionar su controversia y, por otro, le exige que una vez se haya decidido por un foro, no podrá acudir a otro u otros foros para resolver la misma controversia. Es importante aclarar que para efectos de aplicar estas cláusulas, las consultas en los procedimientos de solución de controversias de los TLC en estudio no son consideradas como una actuación contenciosa, por tanto, la posibilidad de elegir el foro no finaliza hasta que la "parte reclamante" recurra a la Comisión ${ }^{31}$ o solicite el establecimiento del panel ${ }^{32}$.

Al igual que en los TLC estadounidenses, los TLC europeos incorporan la cláusula de selección del foro; por ejemplo, el párrafo 4 del artículo 189 del TLC Chile - UE señala que: "[... a) Si una Parte pretende reparar el incumplimiento de una obligación en virtud del Acuerdo de la OMC, deberá recurrir a las normas y procedimientos correspondientes del Acuerdo de la OMC, las cuales serán aplicables no obstante lo dispuesto en el presente Acuerdo. b) Si una Parte pretende reparar el incumplimiento de una obligación en virtud de esta Parte del Acuerdo, deberá recurrir a las normas y procedimientos del presente Título".

En esta cláusula del TLC Chile - UE ${ }^{33}$, las partes en la controversia pueden elegir, de acuerdo con la fuente de la obligación que genera la disputa, tanto el procedimiento de la OMC como el mecanismo de este TLC; asimismo, su elección se encuentra limitada por un deber: iniciado el procedimiento en uno de los foros, no se podrá recurrir al otro ${ }^{34}$.

30 En efecto, cuando una controversia se presenta en un TLC plurilateral, los países demandantes deben realizar consultas, con el fin de convenir un foro único. Si las partes no llegan a un acuerdo, el procedimiento para seguir será según los términos del TLC. Cfr. artículo 2005.2 del TLCAN.

31 Artículo 2005.6 del TlCan. Para profundizar en el tema, cfr. Ojada De Koning, Rodrigo. Solución de controversias conforme al artículo 2005 del TLCAN tras la Ronda Uruguay. En: Memoria del XIX Seminario Internacional de Derecho Internacional Privado y Comparado. Universidad de Guanajuato, 1998, p. 277.

32 Artículo 22.3 (2) del TLC Chile - EE UU, artículo 20.3 (2) del CAFTA - RD, artículo 21.3 (2) del TLC Perú EE UU y artículo 21.3 (2) del TLC Colombia - EE UU.

33 Respecto a la posición chilena sobre la cláusula de selección del foro, el informe emitido por la Cámara de Diputados de Chile señala lo siguiente: "[m]uchas de estas áreas son similares a las de la OMC. Son 'OMC compatibles' y en algunas áreas son simplemente 'reproducción de la $\mathrm{OMC}^{\prime}$, en tanto son necesarias para el cumplimiento de lo acordado bilateralmente, que va más allá de la OMC". Cfr. Cámara de Diputados de Chile. Informe de la Comisión de Relaciones Exteriores, Asuntos Interparlamentarios e Integración Latinoamericana de la Cámara de Diputados de Chile, sobre el proyecto de acuerdo aprobatorio del Acuerdo por el que se Establece una Asociación entre la República de Chile, por una parte, y la Comunidad Europea y sus Estados Miembros por la otra. Boletín 3147-10.

34 Blanc Altemir, Antonio. El Acuerdo de Asociación entre la Unión Europea y Chile: Algo más que un Tratado de Libre Comercio. En: Anuario de Derecho Internacional de la Universidad de Navarra, vol. XX, 2004, pp. 35-110; DelPIANO LiRA, CRISTIÁN. La cláusula de exclusión de foros del Acuerdo de Asociación entre Chile y la Unión Europea en el mecanismo de solución de controversias de la OMC. En: Revista Chilena de Derecho, vol. 33, n. ${ }^{\circ} 2,2006$, pp. 259-284. 
Por otro lado, también es posible encontrar una cláusula de exclusión del foro en el párrafo 4 del artículo 189 del TLC Chile - UE, al señalar que: "[a] menos que las Partes acuerden otra cosa, si una Parte pretende reparar el incumplimiento de una obligación en virtud de esta Parte del Acuerdo que sea en esencia equivalente a una obligación en virtud de la OMC, deberá recurrir a las normas y procedimientos correspondientes del Acuerdo de la OMC, que serán aplicables no obstante lo dispuesto en el presente Acuerdo" ${ }^{\prime \prime 2}$.

Como se puede advertir, el TLC Chile - UE limita la libertad de selección del foro de la parte reclamante y dota al mecanismo multilateral de cierta "primacía" frente al mecanismo bilateral, siempre que se trate de una controversia donde concurran dos elementos: la voluntad de las partes contendientes (quienes tienen un margen de acción para acordar resolver el asunto conforme al TLC Chile - UE, sin recurrir al sistema de solución de diferencias de la OMC) y la naturaleza de las obligaciones en conflicto "en esencia equivalente". Hasta el momento, la jurisprudencia de la OMC no ha logrado aclarar la ambigüedad de este tipo de enunciados ${ }^{36}$.

En cuanto al TLC México - UE, determina, en el párrafo 4 del artículo 47 de la Decisión no. 2 de 2000 y en el párrafo 2 del artículo 43 de la Decisión no. 2 de 2001 del TLC México - UE, que: "[...] El recurso a las disposiciones del procedimiento de solución de controversias establecido en este título será sin perjuicio de cualquier acción posible en el marco de la $\mathrm{OMC}$, incluyendo la solicitud de un procedimiento de solución de controversias".

Nuevamente, esta cláusula de selección del foro del TLC México - UE reproduce el deber de las partes en la controversia de, una vez se haya escogido un foro o procedimiento, no poder acudir a otro u otros. Desde la perspectiva chilena ${ }^{37}$ y mexicana ${ }^{38}$, esta "opción única y definitiva" parecería obvia y simple (tal como se establece en la mayoría

Artículo 189.4 (c) del TLC Chile - UE.

36 Desde la perspectiva de DELPIANO, "[s]i bien no existe aún un criterio definido para entender cabalmente la expresión 'en esencia', seguramente habrá de entenderse como aquella medida que provocaría el mismo perjuicio, tanto en la normativa OMC como en la normativa del TLC". Cfr. DelPIANO. Op. cit., nota 33, p. 268.

37 El informe emitido por la Comisión de Relaciones Exteriores, Asuntos Interparlamentarios e Integración Latinoamericana de la Cámara de Diputados de Chile, a propósito de la regla de exclusión de foros subraya que: "[p]or primera vez en la Unión Europea aceptaron cierta lógica de opción única y definitiva. Pero en los temas que son propiamente OMC, se irá directamente a la OMC. En los temas que sean sustancialmente equivalentes a la OMC, se decidirá caso a caso si se lleva a lo bilateral o a la OMC. Los temas que sean solamente bilaterales van al acuerdo bilateral". Cfr. Cámara de Diputados de Chile. Informe de la Comisión de Relaciones Exteriores, supra, p. 43.

38 En este sentido, el profesor CRUz MiRAMONTES apunta que: "... tuvimos la oportunidad de manifestar inmediatamente nuestro rechazo a la pretensión de los europeos de manejar un mismo asunto al mismo tiempo en dos foros: en el de la OMC y en el que se estableciese en el TLCEU. Difícilmente entendimos en ese momento cómo es que solicitaban algo que constituía una aberración jurídica. (...) Nuestra opinión prevaleció; sin embargo, (...) no significó necesariamente que hayamos obtenido un éxito". Cfr. Cruz Miramontes, Rodolfo. Las Relaciones Comerciales Multilaterales de México y el Tratado de Libre Comercio con la Unión Europea. México: Instituto de Investigaciones Jurídicas de la Universidad Nacional Autónoma de México, 2003, p. 196. 
de TLC estadounidenses); no obstante, fue preciso un importante esfuerzo en las negociaciones con la Unión Europea, ya que en otros acuerdos previos, los países europeos tradicionalmente mantienen abiertas todas las vías o foros de solución de controversias de una manera alternativa y simultáneamente.

Ahora, una de las cláusulas de selección del foro más clara se encuentra en el párrafo 2 del artículo 310 del TLC Andino - UE, que a la letra reza: "[... ] Las controversias relativas a una misma medida que surjan en virtud de este Acuerdo y en virtud del Acuerdo sobre la OMC, podrán ser resueltas de conformidad con este Título o con el ESD a discreción de la Parte reclamante. No obstante, cuando una Parte haya solicitado el establecimiento de un grupo especial de conformidad con el artículo 6 del ESD o un grupo arbitral de conformidad con el artículo 303, dicha Parte no podrá iniciar otro procedimiento sobre la misma cuestión en el otro foro, excepto cuando el órgano competente en el foro escogido no adopte una decisión sobre el fondo de la cuestión por razones de procedimiento o jurisdicción".

Esta cláusula contiene la obligación del Grupo Arbitral de decidir sobre el "fondo" de la controversia; para ello, es necesario que la decisión cumpla con determinadas características, como ser razonable, congruente y fundada en derecho, especialmente en los preceptos del TLC. Adicionalmente, el artículo 310.3 del TLC Andino - UE establece que: "Las Partes entienden que dos o más controversias versan sobre una misma cuestión, cuando involucren a las mismas partes en la controversia, se refieran a la misma medida y versen sobre la misma violación sustancial".

Una novedad importante de este precepto es que admite un concepto amplio de diferencias, o controversia de facto, que se delimita en función de la "medida comercial" u "otras cuestiones" que son objeto de la diferencia, sin restringir esta noción al "fundamento jurídico" o norma concreta del instrumento señalada en el mandato o en los términos de referencia (una controversia de iure).

En definitiva, la efectividad de los mecanismos de solución de diferencias, así como sus deficiencias o lagunas de las normas de conflicto de jurisdicciones, tienen un papel esencial a la hora de elegir el foro ${ }^{39}$. Es por esto que resulta necesario hacer un breve comentario sobre el grado de eficacia o las dificultades en la aplicación de esta norma de conflicto regulada en los TLC estadounidenses y europeos, pues, a primera vista, parecería que la estructura de la cláusula de selección del foro sería razonablemente eficaz para resolver los conflictos jurisdiccionales entre la OMC y los TLC estadounidenses y europeos, dado que sus objetivos son prevenir procedimientos paralelos (parallel proceedings) y procedimientos sucesivos (relitigation). No obstante, en la práctica se presentan diferentes problemas en su aplicación; así, por ejemplo, una cuestión clave que limita la eficacia de la cláusula de selección del foro o del fórum shopping se encuentra en que solo se aplica a los procedimientos en relación con la "misma controversia" o la identidad ratione materiae.

39 GANTZ, DAVID. Dispute Settlement under the NAFTA and the WTO: Choice of Forum Opportunities and Risks for the NAFTA Parties. En: American University International Law Review, vol. 14, n. ${ }^{4}$, 1999, pp. 1101 y ss. 
El alcance de esta limitación dependerá de cómo los Grupos Especiales y el Órgano de Apelación de la OMC o de cómo los paneles de los TLC estadounidenses o europeos interpreten el término "controversia". Para resolver estas cuestiones, generalmente se parte de la distinción entre un concepto restrictivo o controversia de iure, que se define por el fundamento jurídico señalado en el mandato o los términos de referencia, y uno más amplio o controversia de facto, que se delimita en función de la medida comercial u otras cuestiones que son objeto de la diferencia. De modo que si alguno de los órganos resolutorios, ya sea de la OMC o de los TLC, interpreta el término controversia en un sentido restrictivo, la cláusula de selección del foro será ineficaz, puesto que los alegatos jurídicos de violación o incumplimiento de las obligaciones convencionales específicas no serán las mismas.

Desafortunadamente, la jurisprudencia de la OMC arroja muy poca luz respecto al predominio de los dos conceptos: de facto o de iure. Un ejemplo de este aserto se encuentra en el asunto Brasil - Programa de financiación de la exportación para Aeronaves, en el que para determinar si se habían celebrado consultas en relación con la "misma controversia" en dos asuntos, el órgano resolutorio de la OMC examinó si se trataba de la misma práctica ${ }^{40}$. Bajo tal interpretación, se puede inferir que para determinar en qué casos dos diferencias son las "mismas", es importante mirar más allá de si el asunto legal o los fundamentos jurídicos (controversia de facto) son idénticos, es decir, se aplica un concepto amplio de la controversia de iure.

Empero, en otras decisiones, los órganos resolutorios de la OMC han cambiado su posición, aplicando un enfoque legalista o restrictivo, como se puede observar en el asunto India - Medidas que afectan al sector del automóvil, donde el Grupo Especial incorporó a su interpretación la noción de cosa juzgada, para determinar si la controversia en cuestión era la "misma" en comparación con un pronunciamiento anterior, específicamente, el asunto India - Restricciones cuantitativas ${ }^{41}$. Estas referencias mínimas fundadas en la cosa juzgada definen el alcance del enunciado la "misma controversia", a partir de la identidad de las medidas concretas en litigio y los mismos fundamentos jurídicos, adoptando la noción de controversia de iure.

Otro problema de la eficacia de la cláusula de selección del foro en los TLC estadounidenses o europeos se encuentra en que difícilmente podrá ser aplicada o respetada por los órganos resolutorios de la $\mathrm{OMC}^{42}$, ya que el artículo 3.7 del ESD de la OMC establece

40 Textualmente, el Grupo Especial señaló que: ". . consideramos que las consultas y la solicitud de establecimiento se relacionan fundamentalmente con la misma 'diferencia', porque se refieren esencialmente a la misma práctica, es decir, el pago de subvenciones a la exportación en el marco del PROEX". Cfr. Informe del Grupo Especial, en el asunto Brasil - Programa de financiación de las exportaciones para aeronaves (WT/DS46/R), adoptado el 14 de abril de 1999, párr. 7.11

41 Informe del Grupo Especial, en el asunto India - Restricciones cuantitativas a la importación de productos agrícolas, textiles e industriales (WT/DS90/R), adoptado el 6 de abril de 1999.

42 En este sentido, TRACHTMAN manifiesta que la voluntad de los negociadores del ESD no fue establecer una jurisdicción que pudiera aplicar cualquier norma como derecho sustantivo, sino solo el Derecho de la OMC. Adicionalmente, el autor considera que el tenor del ESD "[...] leaves no room for defenses based on another law", y que "... references to respect for the covered agreement, and consistency with the 
como objetivo del mecanismo de solución de diferencias "conseguir la supresión de las medidas de que se trate si se constata que estas son incompatibles con las disposiciones de cualquiera de los acuerdos abarcados". Este enunciado tiene implicaciones concretas para esta cláusula ${ }^{43}$, pues el Derecho de la OMC incorpora de manera directa y clara una obligación para los Grupos Especiales y el Órgano de Apelación: analizar si la medida de que se trata es compatible o no con los "acuerdos abarcados", excluyendo de este examen las medidas que sean incompatibles con disposiciones que no se encuentren en dichos acuerdos.

Sobre esta base jurídica se podría argumentar que la aplicación de la cláusula de selección del foro incorporada en los TLC excedería las funciones de los Grupos Especiales y el Órgano de Apelación de la OMC. De ahí que, como mínimo, resulte cuestionable plantear la posibilidad de que uno de estos órganos resolutivos multilaterales decline su jurisdicción, teniendo como fundamento jurídico de su decisión una norma del $\mathrm{TLC}^{44}$. Esta posición restrictiva del ESD es compartida por un amplio sector de la literatura especializada y por la propia jurisprudencia de la $\mathrm{OMC}$, pues consideran que las controversias en materia comercial presentadas ante el régimen jurídico de la OMC serán resueltas exclusivamente por el mecanismo multilateral (artículo 23 del ESD), con el objeto de preservar sus derechos y obligaciones, y de otorgar a este régimen la seguridad y previsibilidad necesarias ${ }^{45}$.

covered agreements and their objectives in Articles 3.4, 3.5, 3.7, 3.8, 19.1, 22.2 and 22.9 of the DSU would be absurd if other international law were applicable". Cfr. TRACHTMAN, JOEL. Jurisdiction in WTO dispute settlement. En: YerXa, R. y Wilson, B. (eds.). Key Issues in WTO Dispute Settlement: The First Ten Years. Cambridge University Press, 2005, pp. 138-139.

43 Existen otras normas del Derecho de la OMC que dificultan la aplicación de la norma de conflicto de los TLC, como por ejemplo el artículo 7 del ESD que establece el denominado "mandato de los grupos especiales", el cual exige: "Examinar, a la luz de las disposiciones pertinentes (del acuerdo abarcado [de los acuerdos abarcados] que hayan invocado las partes en la diferencia), el asunto sometido al OSD por (nombre de la parte) en el documento [... y y formular conclusiones que ayuden al OSD a hacer las recomendaciones o dictar las resoluciones previstas en dicho acuerdo (dichos acuerdos)". Otros ejemplos, son los artículos $7.2,11$ y 17.6 del ESD.

44 No se puede desconocer que las normas del ESD dificultan la incorporación y aplicación de otras normas de Derecho internacional, en particular de los TLC estadounidenses y europeos, puesto que "la operatividad práctica de las fuentes del Derecho Internacional dentro del mecanismo de solución de diferencias de la OMC se ve influida o afectada por el modelo de norma aplicable que se le ha asignado". Cfr. ZAPATERO. Op. cit., nota 13, p. 76 .

45 En tal contexto, vale la pena recordar que esta es una interpretación desde un enfoque restrictivo de la norma aplicable en la OMC, la cual entiende que el ESD discurre en todo su cuerpo normativo sobre la idea de que cualquier asunto sometido al conocimiento de un Grupo Especial o del Órgano de Apelación deben ser resuelto aplicando las disposiciones de los acuerdos abarcados, en principio, sin incluir en ellas disposiciones más amplias de Derecho Internacional. Cfr. TRACHTMAN, JOEL. The Domain of WTO Dispute Resolution. En: Harvard International Law Journal, vol. 40, 1999. p. 342 a 349; KUYPER, PIETER JAN. The Law of GATT as Special Field of International Law. En: Netherland Yearbook of International Law, vol. XXV, 1994; MARCEAU. Op. cit., nota 3; entre otros. 
Para profundizar en estas cuestiones, en el siguiente apartado se examina la cláusula de exclusión del foro regulada por el Derecho de la OMC, la cual limita e incluso puede anular la eficacia de la cláusula de selección del foro de los TLC estadounidenses y europeos.

\section{LA CLÁUSULA DE EXCLUSIÓN DEL FORO EN LA JURISDICCIÓN OMC COMO UNA PROHIBICIÓN DEL 'FORUM SHOPPING'}

Aunque la mayoría de los acuerdos comerciales prevén diferentes normas de conflicto entre jurisdicciones que tratan de impedir la posible superposición o sucesión de estos foros $^{46}$, parece ineludible que el propio sistema de solución de diferencias de la OMC y cada uno de los TLC estadounidenses y europeos contemplen un mecanismo que se convierte, parafraseando a ZAPATERO, en el "[...] vértice jurisdiccional de su particular pirámide jurídica" 47 . No es de extrañar, por tanto, que la OMC regule un procedimiento de solución de diferencias de naturaleza cuasiautomática y obligatoria. Esta naturaleza se puede comprobar en el párrafo 1 del artículo 23 del ESD, que contiene la cláusula de exclusión del foro ${ }^{48}$ a favor del mecanismo multilateral, cuando se trate de cualquier asunto de interpretación o aplicación de su régimen jurídico ${ }^{49}$, salvo en los casos de ar-

46 Hoy, las relaciones entre los procedimientos de solución de controversias en el orden jurídico internacional no acostumbran crear estructuras de coordinación efectiva, ya sea de forma horizontal o vertical. En este sentido, JENNINGS comenta que "[t]here is no kind of structured relationship between most of them. There is not even the semblance of any kind of hierarchy or system. They have appeared as need or desire or ambitions promoted yet another one. In this particular respect, contemporary international law is just a disordered medley". Cfr. Jennings, RoberT. The Judiciary, International and National, and the Development of International Law. En: International and Comparative Law Quarterly, vol. 45, no. 1, 1996. Para profundizar en estos temas, cfr. ZAPATERO, PABLO. Modern International Law and the Advent of Special Legal Systems. En: Arizona Journal of International \& Comparative Law, vol. 23, n. ${ }^{\circ}$ 1, 2005, p. 73; ABI-SAAB, GeOrges. The Proliferation of Adjudicatory Bodies: Dangers and Possible Answers, Implications of the Proliferation of International Adjudicatory Bodies for Dispute Resolution. En: ASIL Bulletin: Educational Resources on International Law, vol. 9, 1995, p. 21.

47 ZaPATERO. Op. cit., nota 13, p. 382.

48 La cláusula de exclusión del foro adquiere especial relevancia en el actual contexto del Derecho Internacional Privado y del Derecho Internacional, cada vez más fragmentado, con un mayor número de acuerdos y de procedimientos para resolver diferencias. Para entender mejor esta cuestión, cfr. VON MeHrEn, TAYlor. Theory and Practice of Adjudicatory Authority in Private International Law: A Comparative Study of the Doctrine, Policies and Practices in Common- and Civil-Law Systems. En: Recueil des Cours / Collected Cours of the Hague Academic of International Law, vol. 295, 2002; FAWCETT, James (ed.). Declining Jurisdiction in Private International Law. En: Oxford Monographs in Private International Law, 1995.

49 El artículo 23 del ESD materializa la intención de las partes de fortalecer el régimen multilateral del comercio, estableciendo la obligación a los Estados miembros de recurrir al mecanismo de solución de diferencias, lo cual ha sido interpretado por la jurisprudencia como una "cláusula exclusiva para la resolución de diferencias". Cfr. Informe del Grupo Especial, en el asunto Estados Unidos - Artículos 301 a 310 de la Ley de Comercio Exterior de 1974 (WT/DS152/R), adoptado el 22 de diciembre de 1999, párr. 7.43. Regularmente destacado por la literatura especializada como uno de los cambios significativos introducidos por la Ronda Uruguay. Cfr. KESSIE, EDWINI. Enhancing Security and Predictability for Pri- 
bitraje autorizado por el ESD y bajo el control del Órgano de Solución de Deferencias ${ }^{50}$. Simplemente, con el hecho de que un miembro alegue que una medida ha generado un "[...] incumplimiento de obligaciones u otro tipo de anulación o menoscabo de las ventajas resultantes de los acuerdos abarcados, o un impedimento al logro de cualquiera de los objetivos de los acuerdos abarcados ${ }^{\prime \prime 5}$, tiene derecho a iniciar el procedimiento, excluyendo así la competencia de cualquier otro foro o mecanismo para examinar las reclamaciones por violación del régimen de la $\mathrm{OMC}^{52}$.

Otro ejemplo de la naturaleza cuasiautomática y obligatoria se encuentra en el párrafo 1 del artículo 2 del ESD, que reconoce al sistema de solución de diferencias de la OMC como un "elemento esencial para aportar seguridad y previsibilidad al sistema multilateral de comercio", y agrega que "[1]as recomendaciones y resoluciones del OSD no pueden entrañar el aumento o la reducción de los derechos y obligaciones establecidos en los acuerdos abarcados". Así, una consecuencia que podría extraerse de la norma transcrita es que cualquier decisión que declinara la jurisdicción del OSD en favor de la jurisdicción de un TLC podría acarrear la reducción de los derechos y obligaciones,

vate Business Operators under the Dispute Settlement System of the WTO. En: Journal of World Trade, vol. 34, n. $^{\circ} 6,2000$. p. 1.

50 En este caso, Oliveira señala que: "... the arbitral report, since it is issued within the WTO rules, could be enforced by the DSB. It remains to be seen what would be the treatment given to it in practice and if an arbitral report would have the same legal status as panel reports. (...) In addition, both TRIPS (Art. 64) and the SPS Agreement (Art. 11) expressly foresee the possibility of referring disputes to other international organizations or other means of peaceful settlement of disputes for claims based on their provisions". Cfr. Oliveira, Barbara. The Relation between WTO Law and Public International Law: The applicable law in Dispute Settlement at the WTO. University College London LLM Programme, 2005, p. 9. Disponible en internet: SSRN: http://ssrn.com/abstract $=903052$

51 Artículo 23.1 del ESD de la OMC. Como se puede observar, el régimen multilateral del comercio establece un sistema de solución de diferencias de autorreferencia que, según Liñán Nogueras, " . . continúa siendo un modelo con tendencia autónoma, manteniéndose implícitamente la no aplicación de un eventual recurso a los medios de solución de controversias externas a la OMC", de ahí que para este autor el mecanismo multilateral representa "... uno de los más notorios exponentes de las tendencias 'funcionalizadoras' de los sistemas de solución de controversias, esto es, de la tendencia a estructurar sistemas propios para un ámbito más o menos concreto de relaciones internacionales". Cfr. LIÑÁN NOGUERAS, DiEGO JAVIER. El Derecho Económico Internacional (II): El comercio Internacional. En: DíEZ DE Velasco ValLejo, MANUEL. Instituciones de Derecho Internacional. 16 ed. Madrid: Tecnos, 2007, p. 634.

52 En efecto, un miembro de la OMC tiene derecho a iniciar el procedimiento cuasiautomático, no tiene la obligación de demostrar un interés económico específico o jurídico, ni de presentar ninguna prueba de la repercusión en el comercio de la medida impugnada con el fin de iniciar el mecanismo de solución de diferencias (artículo 3.8 del ESD). A este respecto, la profesora STEGER argumenta que el artículo 23 debe interpretarse en el sentido de que el ESD tiene "... not only compulsory jurisdiction over matters arising under the covered agreements, [but that] it also [has] exclusive jurisdiction over such matters". En consecuencia, una vez que se realice la solicitud de un grupo especial o del Órgano de Apelación, este órgano resolutorio se establece automáticamente y su fallo es jurídicamente vinculantes para las partes. Cfr. Steger, Debra. The Jurisdiction of the World Trade Organization. En: American Society of International Law Proceeding, vol. 98, 2004, pp. 142-143. 
dado que estos son determinados en los "acuerdos abarcados" y no en otras normas del Derecho internacional ${ }^{53}$.

Ser el vértice jurisdiccional de su particular pirámide jurídica genera un nuevo matiz de complejidad, que se relaciona con las cuestiones de superposición o conflicto de jurisdicción y, en últimas, con el tema de la jerarquía de las normas de Derecho Internacional. De ahí que la cláusula de exclusión del foro de la OMC es, para el profesor TRACHTMAN, una asignación horizontal de la competencia ${ }^{54}$ que constituye una expresión de la importancia que los miembros de la OMC dan su régimen jurídico.

De la cláusula de exclusión del foro se pueden extraer dos cuestionamientos importantes que se presentan en las relaciones entre los procedimientos de solución de diferencias de la OMC y de los TLC en estudio: primero, ¿será suficiente con invocar la norma de conflicto entre jurisdicciones que determine el foro en los TLC estadounidenses o europeos para que un Grupo Especial o el Órgano de Apelación declinen su competencia o suspendan un procedimiento ante el foro de la OMC?, y segundo, ¿cómo puede el artículo 23 del ESD de la OMC y su proceso casiautomático ser compatible con la preferencia o, en algunas circunstancias, la exclusividad dada al mecanismo de solución de controversias de uno de estos TLC, cuando se trate de obligaciones que son similares en estos dos regímenes?

Estos interrogantes no tienen una respuesta única, tan solo es posible aducir, desde un punto de vista estrictamente normativo, que el artículo 23 del ESD contiene una cláusula específica que excluye otras jurisdicciones para solucionar cualquier controversia sobre violaciones o incumplimiento del Derecho de la $\mathrm{OMC}^{55}$. En tal sentido, el profesor

53 Este argumento se encuentra en el Informe del Órgano de Apelación, en el asunto México - Medidas fiscales sobre los refrescos y otras medias (WT/DS308/AB/R), adoptado el 6 de marzo de 2006, párrafo 53. Adicionalmente, se debe tener en cuenta el artículo 2.4 del ESD, el cual señala que las recomendaciones o resoluciones del OSD "tendrán por objeto lograr una solución satisfactoria de la cuestión, de conformidad con los derechos y las obligaciones dimanantes del presente Entendimiento y de los acuerdos abarcados", de ahí que dichas las resoluciones no deben anular ni menoscabar las ventajas resultantes de los acuerdos abarcados para ninguno de los miembros.

54 En términos de TRACHTMAN, una asignación horizontal de la competencia también tendría diferentes complicaciones jurídicas que ponen en entredicho la validez de la prioridad o la exclusividad de una jurisdicción sobre otra, ya que los TLC estadounidenses y europeos, a la luz del Derecho Internacional, como cualquier tratado, disfrutan del mismo estatus jurídico y son regímenes independientes de la OMC. De manera que en caso de presentarse una controversia entre Estados, que sean al mismo tiempo parte de la OMC y de un TLC, podrían activar cualquiera de sus mecanismos en forma paralela o sucedánea y, por tanto, dos foros y sus órganos resolutivos tendrían competencia para reclamar la jurisdicción final sobre el asunto, con la posibilidad de que lleguen a diferentes, o incluso, decisiones contradictorias. Cfr. TRachtman, Joel. Institutional linkages: Transcending 'Trade and...'. En: The American Journal of International Law, vol. 96, n. ${ }^{\circ}$ 1, 2002, p. 79.

55 Gran parte de la literatura especializada y la jurisprudencia de la OMC entiende que el artículo 23 del ESD busca que las controversias en materia comercial sean resueltas exclusivamente por la OMC, con el objeto de otorgar al régimen multilateral de comercio la seguridad y previsibilidad necesarias. En esta línea, KUYPER ha comentado que "...el carácter cerrado del sistema ha sido reforzado por las nuevas disposiciones del artículo $23 \mathrm{del} \mathrm{ESD.} \mathrm{Este} \mathrm{artículo} \mathrm{enfatiza} \mathrm{fuertemente} \mathrm{que} \mathrm{los} \mathrm{miembros} \mathrm{de} \mathrm{la} \mathrm{OMC}$ deben buscar reparación a las violaciones de obligaciones bajo la OMC y sus anexos solo a través del 
FERNÁNDEZ PONS señala que "[...] no es fácil que una jurisdicción creada con el específico cometido de preservar los derechos y las obligaciones dimanantes de los acuerdos de la OMC llegue a aplicar [...] otras normas internacionales sobre las previsiones de los acuerdos abarcados" ${ }^{\prime \prime 6}$. Asimismo, otro sector de la literatura especializada, particularmente Marceau, opina que: "[...] Article 23 of the DSU reflects the clear intention of WTO Members to ensure that WTO adjudicating bodies can always exercise exclusive jurisdiction on any WTO -related claim. The WTO forum is always a 'convenient forum' for any WTO grievance; in fact it seems to be the exclusive forum for WTO matters ${ }^{\prime \prime} 57$.

Tan es así que esta autora subraya que "[ $\mathrm{t}]$ he WTO will thus often "attract" jurisdiction over disputes with (potential) trade effects even if such disputes could also be handled in fora other than that of the WTO"58. Igualmente, PAUWELYN entiende que: "[m]uch like a vacuum cleaner sucks up its surrounding environment; the new, compulsory and fully automatic WTO dispute settlement system can suck up just about any dispute that is even tangentially related to trade. Any WTO Member has the full and automatic right to sue any other WTO Member about any alleged trade restriction" ${ }^{\prime \prime}$.

Tanto MARCEAU como PAUWELYN tienen la razón cuando señalan que la amplitud de la competencia del ESD de la OMC significa que es posible "attract" o "suck up" la jurisdicción sobre muchas controversias comerciales. Pero esto no implica que la competencia del procedimiento de solución de diferencias de la OMC sea tan amplia como esta terminología podría sugerir, ya que el artículo 23 del ESD no puede prohibir a los órganos resolutorios establecidos por los TLC, o cualquier otro tratado, conocer una controversia de su competencia o suspender un procedimiento sobre las reclamaciones derivadas de sus propias disposiciones que se ejecutan en paralelo o se solapan con las normas de la $\mathrm{OMC}^{60}$. El procedimiento de solución de diferencias de la OMC no está diseñado para ser el único foro. Se trata, por el contrario, de jurisdicciones horizontales que no están subordinadas entre sí. Es por esto que la jurisprudencia o las decisiones de los órganos resolutorios de la OMC y del TLC pueden no solo colisionar, sino también competir

sistema de solución de controversias del DSU y deben suspender concesiones u otras obligaciones solo en concordancia con las normas del DSU". Cfr. KuYPER. Op. cit., nota 44, p. 251.

56 FERnÁNDEZ PONS, XAVIER. La OMC y el Derecho Internacional. Un estudio sobre el sistema de solución de diferencias de la OMC y las normas secundarias del Derecho internacional general. Barcelona: Marcial Pons, 2006, pp. 156 y ss.

57 KWAK y MarCEAU. Op. cit., nota 14, p. 8.

58 Ibidem, p. 3.

59 Pauwelyn, Joost. 'Opening-up' the WTO: What Does it Mean for China? En: Duke Law Faculty Scholarship, Paper 1591, 2006, p. 7. Disponible en internet: http://scholarship.law.duke.edu/faculty_scholarship/1591

60 Graewert, Tim. Conflicting Laws and Jurisdictions in the Dispute Settlement Process of Regional Trade Agreements and the WTO. En: Contemporary Asia Arbitration Journal, no. 1, 2008. p. 293-294. Asimismo, SHANY observa que: "[...] Article 23 of the DSU does not explicitly preclude referring disputes about the "interpretation" of WTO-covered agreements to an external court or tribunal". Cfr. SHANY. Op. cit., nota 16 , p. 184 . 
entre $s^{61}$. No obstante esta observación jurídica, en la práctica parece poco probable que un Grupo Especial o el Órgano de Apelación de la OMC pueda negarse a ejercer su jurisdicción sobre una controversia basándose en la aplicación de una cláusula de selección del foro, incluso cuando la disputa pudiera ser interpretada como "engañosa".

Retomando el análisis de las posiciones de MARCEAU y PAUWELYN, se hallan conclusiones diametralmente opuestas, de acuerdo con el enfoque que cada uno asume. Por un lado, PAUWELYN sostiene enfáticamente que las cláusulas de selección o exclusión del foro de los TLC podrían ser aplicadas por los órganos resolutorios de la OMC, alegando que: "[i]n the end, applying such clauses is nothing extraordinary. All that one would then be doing is giving effect to the explicit agreement between the disputing parties themselves [...] On the contrary, to not give effect to such FTA forum exclusion clauses would go against the sovereign will of the disputing parties, waste resources through duplication of proceedings and create unpredictable trading relations, potentially even conflicting rulings from different international fora"62.

Por otro, MARCEAU, completamente en desacuerdo con PAUWELYN, enfatiza que: "If [forum selection clauses] exist in an RTA and reference to the WTO dispute settlement is addressed nothing seems to stop the WTO panel to proceed over a claim of WTO violation even if this would be contrary to the wording [of the] one RTA treaty ${ }^{\prime \prime}$.

Si bien el régimen jurídico de la OMC no prescinde, de entrada, de la aplicación de las cláusulas de selección del foro o exclusión del foro de otros tratados, sus previsiones y teleología sí limitan la aplicación de estas normas ajenas al Derecho de la OMC o nonWTO law. Más exactamente, las normas del ESD de la OMC hacen que otras disposiciones internacionales solo sean relevantes para la solución de controversias en la medida que no vulneren los "acuerdos abarcados". Sin embargo, esto no impide que los Grupos Especiales o el Órgano de Apelación, en el ejercicio de sus facultades discrecionales, puedan resolver hipotéticos conflictos entre las previsiones de la OMC y los TLC bajo estudio, aplicando las cláusulas de selección del foro o exclusión del foro que son vinculantes para las partes en controversia.

Este punto de vista se enfrenta a diferentes obstáculos, en especial a la lógica jurídica de la solución de controversias del comercio internacional, en la cual: cla resolución de un particular conflicto entre tratados dependerá de qué órgano es el que conoce del conflicto?, ¿de los límites que impone la norma aplicable para resolver el conflicto? y ¿de cómo es interpretada y empleada la norma aplicable? Cualquier respuesta a estos

61 Charney, JonAThan. Is the International Law Threatened by Multiple International Tribunals? En: Recueil des Cours. Collected Courses of the Hague Academy of International Law, t. 271, 1998, p. 129.

62 PAUWELYN, JOOST. Choice of jurisdiction: WTO and regional dispute settlement mechanisms: Challenges, options and opportunities. En: International Centre for Trade and Sustainable Development (ICTSD): dialogue on the "Mexico Soft Drinks dispute: Implications for regionalism and for trade and sustainable development", 2006, p. 6. Disponible en internet: http://www.ictsd.org/dlogue/2006-0530/dialogue_materials/Joost_Pauwelyn_speaker_notes.pdf 
cuestionamientos de los conflictos entre las jurisdicciones de la OMC y de los TLC estadounidenses y europeos, desde una visión realista, se dará caso por caso. Es más, según el profesor ZAPATERO, estas preguntas "[...] no se resuelven, pues, con una respuesta unívoca sino con una respuesta relativa 'en' y 'desde' una perspectiva: la perspectiva de cada mecanismo de solución de diferencias o, si se prefiere, del régimen internacional en el que éste está inserto" ${ }^{\prime \prime 4}$.

\section{LA APLICACIÓN DEL PRINCIPIO DE LA COSA JUZGADA O 'RES JUDICATA' EN LOS CONFLICTOS ENTRE LA JURISDICCIÓN DE LA OMC Y LA JURISDICCIÓN DE LOS TLC ESTADOUNIDENSES Y EUROPEOS}

Ahora, frente a la pregunta ¿cuál es el valor jurídico del principio de la cosa juzgada o res judicata en los conflictos entre jurisdicciones de la OMC y los TLC? Aquí, nuevamente, se encuentran, parafraseando al profesor ZAPATERO, "respuestas relativas". Desde la perspectiva del Derecho de la OMC, técnicamente es poco probable que se aplique el principio de la cosa juzgada en un conflicto jurisdiccional con los TLC bajo estudio. De hecho, los órganos resolutorios de la OMC solamente han utilizado este principio cuando la decisión anterior es de un Grupo Especial o del Órgano de Apelación de la OMC, teniendo en cuenta además que se trate de las mismas partes o ratione personae, las mismas medidas concretas en litigio y los mismos fundamentos jurídicos o ratione materiae. Así ocurrió en el asunto India - Medidas que afectan al sector del automóvil, donde el Grupo Especial incorporó a su interpretación la noción de cosa juzgada para determinar si la controversia en cuestión era la misma en comparación con el pronunciamiento anterior del asunto India - Restricciones cuantitativas a la importación de productos agrícolas, textiles e industriales. Concretamente, el Grupo Especial señaló que: "[... para que el principio de res judicata sea de algún modo aplicable en la solución de diferencias en la OMC debe haber, como mínimo, una identidad fundamental entre el asunto anteriormente resuelto y el presentado al siguiente grupo especial. Esto exige que haya identidad tanto entre las medidas como entre las alegaciones relativas a ellas. También es imprescindible, a los efectos del principio de res judicata o cosa juzgada la identidad de las partes" ${ }^{\prime \prime 5}$.

Según DAVEY y SAPIR, incluso en ese caso donde se podría esperar que el Grupo Especial basara su decisión en el principio de la cosa juzgada o utilizara la noción del precedente para resolverlo, no lo hizo ${ }^{66}$. La jurisprudencia de la OMC se ha limitado a

64 ZAPATERO. Op. cit., nota 13, p. 419-420.

65 Informe del Grupo Especial, en el asunto India - Medidas que afectan al sector del automóvil (WT/ DS146/R), adoptado el 21 de diciembre de 2001, párr. 7.66.

66 Para ilustrar su aserto, DAVEY y SAPIR citan el Informe del Órgano de Apelación, en el asunto Comunidades Europeas - Derechos antidumping sobre la importación de ropa de cama de algodón originario de la India, párrafo 5 del artículo 21 (WT/DS141/AB/RW), adoptado 8 de abril de 2003, párrafos 78-100. Cfr. DAVEY y SAPIR. Op. cit., nota 8, p. 14. El tema del precedente en la jurisprudencia de la OMC se puede profundizar, cfr. JACKSON, JOHN H. Sovereignty, the WTO, and changing fundamentals of International 
señalar que un determinado informe y su interpretación "generan expectativas legítimas para los Miembros" ${ }^{\prime \prime 7}$. Por consiguiente, la jurisprudencia de la OMC y gran parte de la literatura especializada consideran que las controversias en materia comercial presentadas ante el régimen jurídico de la OMC serán resueltas exclusivamente por el mecanismo multilateral (art. 23 del ESD) ${ }^{68}$, con el objeto de preservar sus derechos y obligaciones, y de otorgar a este régimen la seguridad jurídica y previsibilidad necesarias. Bajo esta lógica, a la decisión de un órgano ajeno al régimen multilateral del comercio que tenga por objeto interpretar las obligaciones contenidas en los "acuerdos abarcados" de la OMC no se le dará, en principio, ninguna "cortesía judicial" o reconocimiento como a un asunto que ha hecho tránsito a cosa juzgada.

En esta misma línea, el profesor PAUWELYN, al analizar el asunto México - Medidas fiscales sobre los refrescos y otras bebidas y el asunto Estados Unidos - Madera blanda, reconoce que "[a]lthough clearly dealing with the same broader dispute on lumber or sweeteners, the different rulings out of NAFTA and/or the WTO are not, strictly speaking, in a relation of res judicata" 69 . Claro está, el mismo autor subraya que "[...] the absence of res judicata should not lead one tribunal to completely ignore the work of the other ${ }^{\prime \prime 70}$. Parecería que sin importar que se presenten en ambas jurisdicciones (OMC / TLC) las mismas partes y la cuestión en litigio esté relacionada, jurídicamente hablando, el "derecho aplicable" no es el mismo. Los alegatos de defensa específicos que presentan las partes en la diferencia solo derivan de uno de los tratados, o los plazos, los derechos procesales, todo ello lleva a soluciones que pueden o no ser diversas en las dos jurisdicciones. De ahí que resulta poco probable que, en la práctica de la jurisdicción de la OMC, se logre aplicar el principio de la cosa juzgada, así las disposiciones controvertidas sean reproducidas literalmente en los dos foros.

Sin embargo, esta respuesta no está del todo acabada, ya que los conflictos entre la jurisdicción de la OMC y la jurisdicción de los TLC son más que un simple ejercicio teórico o un hecho aislado, como se demuestra en algunas diferencias, como el asunto México - Medidas fiscales sobre los refrescos y otras bebidas, el asunto Estados Unidos - Madera blanda, el asunto Argentina - Derechos antidumping definitivos sobre los

Law. Cambridge: Cambridge University Press, 2006, pp. 176 y ss.; JACKSON, JOHN H. The Jurisprudence of GATT \& the WTO. Cambridge: Cambridge University Press, 2002, pp. 125-129.

67 Informe del Órgano de Apelación, en el asunto Japón - Impuestos sobre las bebidas alcohólicas (WT/ $\mathrm{DS} 8 / \mathrm{AB} / \mathrm{R}, \mathrm{WT} / \mathrm{DS} 10 / \mathrm{AB} / \mathrm{R}, \mathrm{WT} / \mathrm{DS} 11 / \mathrm{AB} / \mathrm{R})$, adoptado el 4 de octubre de 1996 . Otro informe trascendental para este tema es el asunto Estados Unidos - Medidas antidumping definitivas sobre el acero inoxidable procedente de México (WT/DS344/AB/R), adoptado el 30 de abril de 2008.

Informe del Grupo Especial, en el asunto Comunidades Europeas - Medidas que afectan el comercio de embarcaciones comerciales (WT/DS301/R), adoptado el 3 de septiembre de 2003; Informe del Grupo Especial, en el asunto Estados Unidos - Artículos 301 a 310 de la Ley de Comercio de 1974 (WT/DS152/R), adoptado el 22 de diciembre de 1999.

69 PauWELYn, Joost. Adding Sweeteners to Softwood Lumber: the WTO-NAFTA 'Spaghetti Bowl' is Cooking. En: Journal of International Economic Law, vol. 9, n. ${ }^{\circ}$ 1, 2006, p. 4.

Ibidem, p. 5. 
pollos procedentes del Brasil, el asunto Brasil - Medidas que afectan la importación de neumáticos recauchutados, entre otras. La complejidad de las relaciones entre el régimen jurídico de la OMC y los TLC en estudio exige mayores esfuerzos hermenéuticos frente a sus conflictos de jurisdicciones, por esto, no se entiende la visión "miope" de los órganos resolutorios de la OMC, quienes son renuentes a aplicar la cosa juzgada, que exige no solo la coincidencia en las partes en los dos foros, sino también el mismo objeto o petitum, y la misma causa de la acción o causa petendi. Esta última condición, interpretada en sentido estricto, solo se cumple cuando los fundamentos jurídicos de la decisión previa del procedimiento regulado por un TLC correspondan a normas de remisión al régimen jurídico de la OMC o sean normas reproducidas literalmente de la OMC. Desde esta perspectiva, es acertada la interpretación de PAUWELYN y SALLES, cuando apuntan que: "[t]he reluctance of WTO panels and the Appellate Body to apply the principle of res judicata is difficult to understand. If the Appellate Body decides to apply judicial principles on burden of proof, good faith, and due process - on which nothing is explicitly said in the DSU- there is no reason for it to reject the principle of res judicata. The WTO reluctance to apply the principle of res judicata is all the more surprising because res judicata is only rarely triggered in international litigation" ${ }^{\prime \prime 1}$.

Por otra parte, sin desconocer la importancia de la interpretación de los órganos resolutorios de la OMC sobre la norma de conflicto, no se debe perder de vista la existencia de una presunción de legalidad respecto a las decisiones de los paneles de los TLC, que se derivan directamente de los instrumentos internacionales que los han creado ${ }^{72}$.

Otro escenario para el principio de la cosa juzgada se presenta en la jurisdicción de los TLC, específicamente en las decisiones del panel en el marco del Acuerdo de Libre Comercio entre Canadá y Estados Unidos -ALCCEU- de 1989 y del TLCAN de 1994, en donde existen diferentes asuntos que aluden a las disposiciones del GATT de 1947 y de la OMC, incluso se apoyan o utilizan la interpretación hecha por los Grupos Especiales y el Órgano de Apelación de estas normas que, además de considerarse como un criterio auxiliar de interpretación, en algunos casos han llegado a actuar como un argumento de autoridad. De hecho, parece razonable afirmar que, en ocasiones, estas decisiones de los órganos resolutorios de la OMC han operado como un auténtico "precedente ${ }^{\prime \prime 73}$ para

71 Para PAUWELYN y SALLES, esta situación podría cambiar "... if tribunals were willing to soften the three criteria for res judicata to apply. To do so they could borrow from common law notions such as 'issue estoppel' or civil law notions such as 'related actions". Cfr. PAuWElYn y SALlES. Op. cit., nota, 18, pp. $102-104$.

72 Aunque la decisión de los órganos resolutorios no tenga el mismo estatus que una disposición del tratado en virtud del Derecho Internacional, la validez y fuerza vinculante de dicha decisión se deriva del tratado constitutivo que define la competencia de cada uno de ellos. Por tanto, un Estado sujeto a este tiene la obligación convencional de darle cumplimiento. Cfr. International Court of Justice Reports of judgments, in the Certain Expenses of the United Nation, advisory opinions and orders, Advisory opinion of 20 July 1962 , p. 168.

73 A pesar de que el stare decisis o precedente no se reconoce de manera explícita en los TLC estadounidenses, la tradición jurídica de Common Law impulsa a sus paneles a tener en cuenta las decisiones de los Grupos Especiales del antiguo GATT y de los órganos resolutorios de la OMC. 
la jurisdicción de los TLC. Así, por ejemplo, en el asunto Estados Unidos - Regulación de la Langosta ${ }^{74}$, el panel examinó la controversia en la interpretación del artículo XI y del artículo III del GATT de 1947 (que se incorporan mediante normas de remisión, en el artículo 407 y el artículo 501 del ALCCEU). En este caso, el panel señala explícitamente que algunas decisiones de los Grupos Especiales del GATT constituyen precedente ${ }^{75}$, y al mismo tiempo, modera su interpretación al señalar que: "[s]ome members of the Panel consider that the wording of GATT Articles III and XI provides the basic elements necessary to classify a measure. Nevertheless, they were of the opinion that, in addition to the GATT language, the interpretation given to these GATT Articles by the drafters of the Agreement and by Panel Reports provides helpful comments on the scope of Articles XI and III"76.

Bajo este panorama, aunque no exista ningún informe de los paneles de los TLC que aplique el principio de la cosa juzgada, es probable que en el futuro se aplique este principio para evitar decisiones sucedáneas que puedan ser diferentes o contradictorias con los informes de la jurisdicción de la OMC que resuelvan una "misma controversia".

74 En estricto sentido, en este asunto la controversia se presenta entre dos posiciones: "Canada argued that the 1989 amendment is a border measure imposing a prohibition on imports of Canadian subsized lobsters and is therefore in violation of GATT Article XI. The United States argued that the 1989 amendment is rather an internal measure applied to the marketing and sale of sub-sized lobsters and is therefore subject to GATT Article III. Cfr. Informe final del Panel del TLCAN, en el asunto Estados Unidos - Regulación de la Langosta (USA 89-1807-01), adoptado el 25 de mayo 1990, párr. 8.1.1.

75 En efecto, el panel examinó como precedentes el Informe del Grupo Especial del GATT, asunto Canadá - Aplicación de la Ley sobre el examen de la inversión extranjera (IBDD 30S/151-182), adoptado el 7 de febrero de 1984; Informe del Grupo Especial del GATT (L/4687), en el asunto Comunidades Europeas Programa de precios mínimos de importación, licencias y depósitos de garantía de determinadas frutas y hortalizas (BISD 25S/68/107), adoptado el 18 de octubre de 1978 e Informe del Grupo Especial del GATT (L/6309), en el asunto Japón - Comercio de semiconductores (BISD 35S/116-163), adoptado el 4 de mayo de 1988, y determinaron que "there is no GATT Panel precedent in which a complete prohibition on the sale, use or transportation of imported products, as is the 1989 amendment in regard to Canadian sub-sized lobsters, was held to fall within Article III". Cfr. Informe final del Panel del TLCAN, en el asunto Estados Unidos - Regulación de la Langosta, supra, párr. 8.3.3. Ahora bien, en decisiones posteriores del panel del ALCCEU matiza su posición respecto a la jurisprudencia del GATT como "precedente", al determinar que esta no le es vinculante, sino que constituye "panel opinion pursuant to GATT", es decir, como meras "opiniones". Cfr. Informe final del Panel del TLCAN, en el asunto Estados Unidos - Magnesio puro y aleación (USA-92-1904-03), adoptado el 16 de agosto de 1993, p. 9.

76 Ibidem, párr. 8.3.1. Otro caso donde podemos evidenciar la interacción a través de las normas de remisión en la jurisprudencia del ALCCEU es el asunto Canadá - Requerimientos para el desembarco del salmón y del arenque de la costa del Pacífico, en el cual se analiza el conflicto de aplicación del artículo XX (g) y artículo XI del GATT incorporados mediante las normas de remisión, en el artículo 407 y el artículo 1201 del ALCCEU. Es más, un miembro del panel llega a señalar que "... did not believe that existing GATT rules or previous GATT decisions provide a clear basis for reaching a judgment in the present case as to whether the landing requirement constitutes a restriction within the meaning of Article XI: 1, and was not prepared to make a decision on this issue. This member was of the view that the consistency of landing requirements with GATT rules raises conceptual issues that may deserve further consideration by the GATT Contracting Parties". Cfr. Informe final del Panel del TLCAN, en el asunto Canadá - Requerimientos para el desembarco del salmón y del arenque de la costa del pacífico (CDA-89-1807-01), adoptado el 18 de octubre de 1989, párr. 6.14. 


\section{OBSERVACIONES FINALES}

Existe una ineludible realidad en la regulación del comercio internacional: una constante fragmentación que se configura a partir de una pluralidad de regímenes jurídicos y sus mecanismos de solución de diferencias, los cuales normalmente interactúan de manera horizontal en el marco del Derecho Internacional, a menos que el propio régimen reconozca expresamente la subordinación o la mayor jerarquía jurídica de otro régimen. Justamente por ello, las relaciones entre el Derecho de la OMC y los TLC pueden generar, según ZAPATERO, "perspectivas jurídicas divergentes respecto a una misma cuestión"77, que ni si quiera pueden ser resueltas del todo por las normas generales sobre conflictos entre tratados ${ }^{78}$. Estas cuestiones tampoco han sido resueltas, hasta el momento, por el Derecho de la OMC o su sistema de solución de diferencias. No existe una clara posición de sus órganos resolutorios sobre diferentes problemas: el Derecho aplicable, los conflictos de jurisdicciones o la propia noción de controversia. Por tanto, se trata de "soluciones jurídicas no definidas"79 o "soluciones a medias", que no tienen una respuesta única en la práctica. Justamente, es posible encontrar respuestas diferentes, dependiendo del régimen desde el que se realiza el análisis.

De no resolverse esta fragmentación, o mejor, de continuar la ausencia de coherencia, los mecanismos de solución de controversias de los TLC en estudio y de la OMC inevitablemente llegan y seguirán llegando a aproximaciones diferentes sobre idénticas cuestiones sustanciales y procedimentales. Como de hecho ya ha ocurrido en algunas decisiones de los órganos resolutorios multilaterales y del TLCAN que se han solapado o han sido contradictorias. Un ejemplo de ello son los mencionados asuntos sobre los azúcares entre Estados Unidos y México y la madera entre Estados Unidos y Canada. También se observan estos conflictos de jurisdicción con otros procesos de integración, como el MERCOSUR, donde en el asunto Argentina - Derechos antidumping definitivos sobre los pollos procedentes del Brasil y en el asunto Brasil - Medidas que afectan la importación

77 En otras palabras, para el profesor ZAPATERO, en la pluralidad de regímenes internacionales no se observan las normas generales sobre solución de conflictos de tratados (artículo 30 de la Convención de Viena), debido a que "[e]l funcionamiento de estas relaciones tiene origen en las particulares políticas jurisdiccionales, legislativas (p. ej. diseño de la norma aplicable), hábitos y actitudes (colectivas e individuales) de los operadores legales que actúan en su seno y puede o no corresponder con las soluciones que prescribe la aplicación de las normas generales sobre conflictos de tratados". Cfr. ZAPATERO. Op. cit., nota 13 , pp. 410-411.

78 En este sentido, SINCLAIR señala que las normas generales sobre conflictos entre tratados del artículo 30 de la Convención de Viena no son "enteramente satisfactorias", ya que estas contienen un modelo simplificado que no responde de forma correcta a las actuales necesidades del orden jurídico internacional. Cfr. Sinclair, IAn MCTaggart. The Vienna Convention on the Law of Treaties. 2 ed. Manchester University Press, 1984, p. 98.

79 En opinión del profesor HUDEC, en ocasiones, en el Derecho Internacional económico se encuentran normas con apariencia de soluciones jurídicas en las que, en realidad, no se ha llegado a ninguna solución. Cfr. Hudec, Robert. International Economic Law: The Political Theatre Dimension. En: University of Pennsylvania Journal of International economic Law, vol. 17, n. ${ }^{\circ} 1,1996$, p. 9. 
de neumáticos recauchutados, la jurisdicción de la OMC llegó a decisiones contrapuestas respecto a la decisión de la jurisdicción del MERCOSUR, lo cual tiene el potencial no solo para crear problemas de ausencia de una jurisprudencia coherente, sino también una amenaza para la estabilidad y previsibilidad del sistema de comercio internacional. Desafortunadamente, es probable que estas cuestiones continúen sin resolverse, como los TLC continúan creciendo cualitativa y cuantitativamente ${ }^{80}$, mientras que la Ronda de Doha permanece en una larga soñolencia. Es aquí donde tiene importancia el principio de la cosa juzgada o res judicata, que puede ser una opción para aportar claridad y seguridad respecto a este tipo de solapamientos entre jurisdicciones.

80 Así se observa en la poca, pero discutida, jurisprudencia de los paneles de estos acuerdos, específicamente en el TLCAN, que, según Morgan, "[... It should be noted that there has been 32 cases among NAFTA parties in the WTO, compared to only 3 sate-state cases among these countries in the NAFTA forum. However, not surprisingly, under NAFTA Chapter 19 (Binational panels for Antidumping and Countervailing duties) there have been 58 disputes". Cfr. Morgan, David. Dispute Settlement under PTAs: Political or Legal?. En: Legal Studies Research Paper n. ${ }^{\circ}$ 341, University of Melbourne Law School, 2007, p. 253. Asimismo, cfr. DaveY, William. Dispute Settlement in the WTO and RTAs: A Comment. En: Bartels. L. y Ortino, F. (eds.). Regional Trade Agreements and the WTO Legal System. Nueva York: Oxford University Press, 2006, pp. 350-351. 